\title{
pH e condutividade do cloridrato de procaína em diferentes concentrações utilizadas em terapia neural
}

\author{
Leonardo Rocha Vianna ${ }^{a}$, Bruna Aparecida Lima Gonçalves ${ }^{b}$
}

\author{
${ }^{a}$ Acupunturista, Medicina Tradicional Chinesa, Homeopata, Terapeuta Neural, Iridologista, Fitoterapeuta, Quiroprata. \\ Universidade Federal de Minas Gerais (UFMG), Belo Horizonte, MG, Brasil. \\ ${ }^{b}$ Acupunturista, Medicina Tradicional Chinesa, Terapeuta Neural. Universidade Federal de Minas Gerais (UFMG), Belo \\ Horizonte, MG, Brasil.
}

RESUMO O cloridrato de procaína é um anestésico local utilizado na terapia neural com resultados surpreendentes em diferentes tipos de pacientes e tratamentos. A terapia neural foi desenvolvida principalmente, pelos irmãos alemães Huneke e é praticada há mais de 100 anos. Em 1940, Ferdinand Huneke verificou o desaparecimento súbito de uma dor no ombro de um paciente após aplicação em uma cicatriz de osteomielite na perna. Esse tratamento é difundido na Alemanha, Áustria, Argentina, Canada, Colômbia, Costa Rica, Cuba, Espanha, Estados Unidos, México, Suíça e hoje vem se difundido também no Brasil e vários outros países. Tem reconhecimento internacional como método curativo e eficaz em muitas enfermidades. Para conhecer melhor as características da principal substância e das soluções utilizadas na terapia neural, bem como a velocidade de resposta do organismo após sua aplicação, foram realizadas experimentos para estabelecer o comportamento elétrico de seus componentes. O objetivo desse trabalho é demonstrar e avaliar o pH e a condutividade de diferentes concentrações de soluções de cloridrato de procaína.

PALAVRAS-CHAVE: anestésicos locais; autocura; potencial de membrana; poração celular; repolarização.

Aceito 26 de novembro de 2020 Publicado online 21 de janeiro de 2021

Cite este artigo: Vianna e Gonçalves (2021) pH e condutividade do cloridrato de procaína em diferentes concentrações utilizadas em terapia neural. Multidisciplinary Science Journal 3: e2021002, doi: 10.29327/multiscience.2021002.

\section{$\mathrm{pH}$ and conductivity of procaine hydrochloride in different concentrations used in neural therapy}

ABSTRACT Procaine hydrochloride is a local anesthetic used in neural therapy with surprising results in different types of patients and treatments. neural therapy was developed mainly by the German brothers Huneke and has been practiced for over 100 years. In 1940, Ferdinand Huneke noticed the sudden disappearance of a pain in the shoulder of a patient after application on an osteomyelitis scar on the leg. This treatment is widespread in Germany, Austria, Argentina, Canada, Colombia, Costa Rica, Cuba, Spain, United States, Mexico, Switzerland and today it is also spreading in Brazil and several other countries. It has international recognition as a curative and effective method in many diseases. To better understand the characteristics of the main substance and solutions used in neural therapy, as well as the response speed of the organism after its application, experiments were carried out to establish the electrical behavior of its components. The objective of this work is to demonstrate and evaluate the $\mathrm{pH}$ and conductivity of different concentrations of procaine hydrochloride solutions.

KEYWORDS: local anesthetics; self-healing; membrane potential; cell poration; repolarization.

\section{Introdução}

A procaína é o primeiro anestésico local sintético criada por Alfred Einhorn em 1905. É um éster metabolizado em ácido para amino benzoico (PABA) e dietilamina etanol (DEAE) degradado pelas acetilcolinesterases plasmáticas. É 
uma substância dielétrica que ativa eletricamente as células permitindo a repolarização celular, a troca de íons pela membrana plasmática e influência nas funções vitais das células (Muri 2010; Bulcão 2011; Garcia e Machado 2017).

Desde 1906, Spiess já observou a ação anti-inflamatória da procaína. Em 1925, Ferdinand e Walter Huneke trataram com êxito uma enxaqueca não responsiva a tratamentos de sua irmã e outros quadros clínicos através da aplicação de procaína intravenosa e desconfiaram da sua ação elétrica e a distância. Em 1934, Dr. Leriche observou o desaparecimento instantâneo da dor após a injeção de anestésicos locais em uma cicatriz, demonstrando o fenômeno instantâneo (Fischer 2012). Posteriormente, este fenômeno foi batizado pelos irmãos Huneke de fenômenos em segundos (Castro 2011).

A terapia neural é difundida na Alemanha, Áustria, Argentina, Canada, Colômbia, Costa Rica, Cuba, Espanha, Estados Unidos, México, Suíça (Vianna e Gonçalves 2016). Pode ser utilizada em numerosas enfermidades como transtornos reumáticos, neurológicos, ginecológicos, enxaquecas, amigdalites, sinusites, otites, asma, afecções dermatológicas dentre outras (De La Torres Roses e Mendonza 2008). Também é utilizada para dor miofacial, dor visceral, síndrome de dor pós amputação, neuralgia herpética, vulvodina, colite crônica, zumbido (tinidos), quadros oncológicos e Alzheimer (Weinschenk 2012). A procaína tem efeito epigenético em estágios de câncer tanto in vitro quanto in vivo e aumenta a atividade antitumoral quando combinada com outros fármacos (Gonçalves et al 2020). Além das ações anti-inflamatória e antimicrobiana (Cassuto et al 2006; Adler et al 2017).

Pode se utilizar anestésicos locais, como a procaína e lidocaína, nas concentrações de 0,1 a 1\% (Cruz e Fayad 2011). Bravo-Monsalvo et al (2008) utilizaram cloridrato de procaína a $0,7 \%$ por via endovenosa na dose de $0,1 \mathrm{mg} / \mathrm{kg}$ e intradermal na dose máxima de $7 \mathrm{mg} / \mathrm{kg}$ em cães com dermatite atópica e obtiveram excelentes resultados.

A associação do cloridrato de procaína com bicarbonato de sódio forma um "cluster" que altera o pH e diminui o ardor na hora da aplicação e potencializa os resultados, a administração endovenosa demonstrou ação antirreumática, antitumoral, anti-inflamatória, analgésica e aumento da vitalidade nos pacientes (Reuter 2017). A procaína apresenta $290 \mathrm{mV}$ e possui efeito repolarizante celular (Burrel Serrat 2008; Castro 2011).

Segundo Suzuki (2009), a membrana celular é uma barreira para a passagem de substâncias entre o meio intracelular e extracelular. Quando um campo elétrico, suficientemente intenso é aplicado na célula, há uma redução desta barreira que permite a transferência de íons e moléculas solúveis em líquido extracelular para o interior da célula. O aumento da permeabilidade de uma membrana celular é acompanhado por aumento da condutividade da membrana (Pavlin et al 2005).

A membrana celular apresenta uma natureza hidrofóbica devido a bicamada lipídica na face interna da membrana, isto representa uma barreira para o transporte da maioria das moléculas solúveis em água. Quando um forte campo elétrico é aplicado, a membrana celular torna-se mais permeável, permitindo assim a entrada de várias moléculas, que pode ser usado como um método para a introdução de certos medicamentos ou genes na célula (Pavlin et al 2002; Pavlin et al 2005).

A poração celular e a fusão celular são importantes métodos biológicos que possibilitam uma variedade de aplicações, incluindo transfeç̧ão de genes, entrada de drogas, produção de anticorpos, e hibridização celular. Nos últimos anos, foi descoberto que a poração celular e a fusão celular podem ser induzidas pela aplicação de um pulso de campo elétrico intenso (Chang 1989).

Segundo Ramos et al (2006), a eletroporação tem sido aplicada em vários campos da bioquímica, biologia molecular, biomedicina, pesquisa, medicina e oncologia. Esta é utilizada como um maneira de aumentar a eficiência das vacinas de DNA, para ativar a imunidade contra o câncer; na eletroquimioterapia, na transferência de quimioterápicos como cisplatina para dentro de células tumorais cutâneas; na transferência de plasmídeos (DNA) e na fusão de células, como ferramenta do melhoramento genético; no transporte de moléculas (vitaminas, lidocaína, entre outras) para a pele; e inserção de proteínas na membrana celular (Lebar e Miklavči 2001; Sanchez et al 2019).

A dinâmica de abertura e fechamento, bem como o tamanho e quantidade de poros sofrem a influência de vários fatores como: campo elétrico aplicado e propriedades do meio celular como condutividade interna e externa do meio. Quando um tecido biológico ou uma suspensão de células são excitados por um campo elétrico externo, ocorrem movimentações iônicas e os íons acumulam-se em ambos os lados da membrana celular (Suzuki 2009).

O objetivo desse trabalho é demonstrar e avaliar o pH e a condutividade de diferentes concentrações de soluções de cloridrato de procaína. 


\section{Material e Métodos}

Os dados foram avaliados em laboratório farmacêutico. Realizados em triplicatas e aplicou se análise estatística descritiva da média com desvio padrão.

As soluções foram preparadas utilizando cloridrato de procaína a $50 \%$ e bicarbonato de sódio $8,4 \%$ em solução fisiológica a 0,9\%. Como exemplo: Para obter uma diluição de cloridrato de procaína a 0,7\%, mistura-se em uma bolsa de $250 \mathrm{ml}$ de solução fisiológica a 0,9\%, 3,5 ml de cloridrato de procaína a 50\% e 5,0 ml de bicarbonato de sódio a 8,4\%. Retira-se o volume injetado, que nesse caso foi $8,5 \mathrm{ml}$, e o volume extra da bolsa que normalmente é de $5 \%$ do valor total.

Foi utilizado o aparelho phmetro e condutivimetro de bancada (Quimics), o qual possui dois eletrodos, um de metal e outro de vidro que realizam as medições (Figura 1).

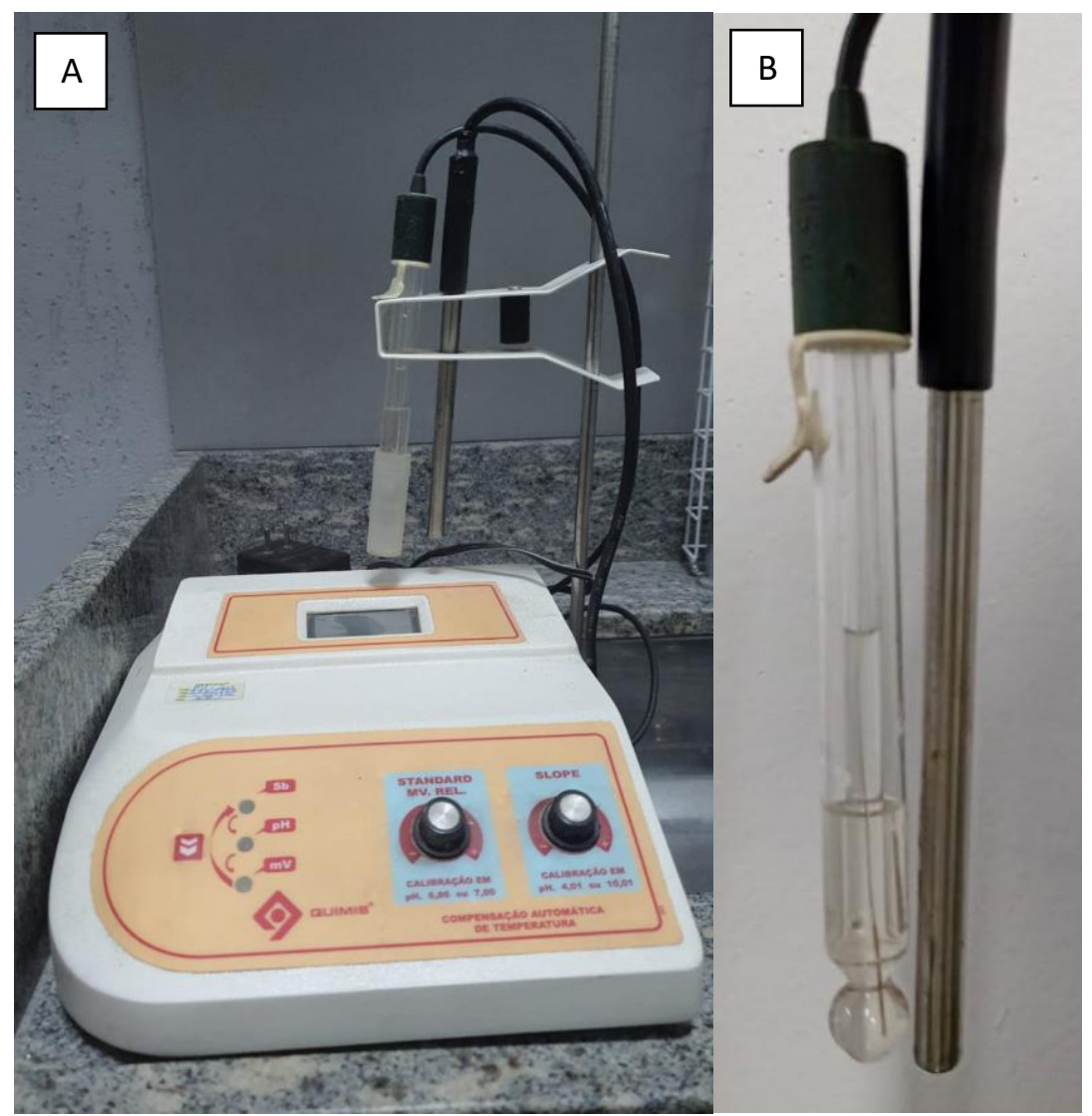

Figura 1 (A) Aparelho da marca Quimics utilizado para as medições de pH e condutividade das substâncias e (B) seus eletrodos de vidro e metal.

\section{Resultados e Discussão}

Os estudos das substâncias com possível utilização em terapia neural iniciam com a informação de sua composição, $\mathrm{pH}$ e condutividade (Tabela 1). O potencial hidrogênico $(\mathrm{pH}$ ) é a capacidade de um material liberar íons hidroxila indica acidez, neutralidade ou alcalinidade de uma solução, sendo o valor 7 considerado neutro, 1 muito ácido e 14 extremamente alcalino (Canali 2015).

Segundo Vianna e Gonçalves (2017), os anestésicos locais têm ação repolarizante, e são capazes de estimular eletricamente as células. A célula normal possui um potencial elétrico de repouso que varia de \pm 40 a \pm 90 milivolts, resultado da presença de íons de sódio e potássio. Se há estímulos constantes, fortes ou irritativos, a célula pode perder a capacidade de se repolarizar, permanecendo despolarizada (González-Rivas 2018). Essas regiões corporais que contêm células modificadas do ponto de vista eletroquímico, e estão relacionadas com o processo patológico do organismo podem ser campos interferentes que geram estímulos irritativos ao corpo (Gonçalves et al 2020). 
Tabela 1 Avaliação de Soro fisiológico com cloridrato de procaína e bicabornato de sódio em diferentes concentrações.

\begin{tabular}{|c|c|c|}
\hline Produto testado & $\mathrm{pH}$ & Condutividade $(\mathrm{mV})$ \\
\hline $\begin{array}{l}\text { Cloridrato de procaína 0,7\% c/ bicarbonato de sódio } \\
\text { diluída há } 21 \text { dias }\end{array}$ & $7,24 \pm 0,06$ & $-93,0 \pm 0,06$ \\
\hline $\begin{array}{l}\text { Cloridrato de procaína } 0,7 \% \text { c/ bicarbonato de sódio } \\
\text { diluída há } 21 \text { dias - dinamizada } 100 x\end{array}$ & $7,08 \pm 0,28$ & $-82,50 \pm 0,28$ \\
\hline $\begin{array}{l}\text { Cloridrato de procaína } 0,7 \% \text { c/ bicarbonato de sódio } \\
\text { diluída há } 21 \text { dias - dinamizada } 200 x\end{array}$ & $7,15 \pm 0,07$ & $-95,00 \pm 0,07$ \\
\hline $\begin{array}{l}\text { Cloridrato de procaína } 0,7 \% \text { c/ bicarbonato de sódio } \\
\text { diluída há } 21 \text { dias exposta a média/alta temperatura } \\
\text { (armazenada em veículo automotivo) }\end{array}$ & $7,29 \pm 0,31$ & $-95,00 \pm 0,07$ \\
\hline $\begin{array}{l}\text { Cloridrato de procaína } 0,7 \% \text { c/ bicarbonato de sódio } \\
\text { diluída há } 24 \mathrm{~h}\end{array}$ & $6,65 \pm 0,47$ & $-207,00 \pm 0,04$ \\
\hline $\begin{array}{l}\text { Cloridrato de procaína } 0,35 \% \text { c/ bicarbonato de sódio } \\
\text { diluída há } 24 \text { horas }\end{array}$ & $6,49 \pm 0,04$ & $-197,50 \pm 0,31$ \\
\hline $\begin{array}{l}\text { Cloridrato de procaína 0,26\% c/ bicarbonato de sódio } \\
\text { diluída há } 24 \text { horas }\end{array}$ & $6,37 \pm 0,47$ & $-180,00 \pm 0,28$ \\
\hline $\begin{array}{l}\text { Cloridrato de procaína } 0,175 \% \text { c/ bicarbonato de } \\
\text { sódio diluída há } 24 \text { horas }\end{array}$ & $6,50 \pm 0,04$ & $-200,00 \pm 0,28$ \\
\hline
\end{tabular}

Segundo Burrel Serrat (2008) os anestésicos locais em baixas concentrações apresentam $290 \mathrm{mV}$ de condutividade, mas a medição máxima encontrada neste trabalho foi de $207 \mathrm{mV}$.

Os aparelhos com suas características individuais, sensibilidades de medição, bem como a temperatura ambiente podem alterar os resultados do estudo. O tempo após a diluição da droga tem efeito sobre o pH e a condutividade. $\mathrm{A}$ dinamização da solução pode apresentar efeitos benéficos no que diz respeito a manutenção do percentual de procaína ativa, condutividade e no tempo de degradação da procaína após diluída na bolsa (informação verbal) ${ }^{1}$.

1 Jacqueline Casula, farmacêutica do Grupo Citopharma de Belo Horizonte, no Simpósio de Novidades em terapia neural em 02 de junho de 2017, Belo Horizonte/MG.

\section{Conclusões}

A avaliação de pH e condutividade são a base para que em breve tenhamos mais opções de substâncias e diluições a serem utilizadas na terapia neural.

O sistema convencional de ensino da terapia neural faz com que o profissional busque os campos interferentes, doenças crônicas, lesões, cirurgias, fraturas, acidentes e locais de incomodo ou dor, com o objetivo de que após a aplicação o corpo se auto cure e realize auto eco organização. Isto ocorre através da ativação da membrana celular após a aplicação da substância dielétrica. Quanto menor a concentração da substância, menor será seu risco tóxico. Quanto mais próximo a 7,4 estiver o $\mathrm{pH}$, menos dor no local de aplicação.

Quanto ao potencial de membrana da célula enferma, ainda não foram encontrados trabalhos consistentes que permitam afirmar qual a condutividade mínima para a ativação celular. Este trabalho abre novas opções para o início de diluições para uso clínico e experimental.

\section{Agradecimentos}

Farmácia Casa das Fórmulas, Belo Horizonte/MG.

\section{Declaração de conflito de interesses}

Não há conflito de interesses entre os autores.

\section{Referências}

Adler DMT, Damborg P, Verwilghen DR (2017) The antimicrobial activity of bupivacaine, lidocaine and mepivacaine against equine pathogens: An investigation of 40 bacterial isolates. The Veterinary Journal 223:27-31.

Bulcão RP, Arbo MD, Roehrs M, Paniz C, Cervi FL, Thiesen FV, Leal MB, Garcia SC (2011) Procaína: Efeitos farmacológicos e toxicológicos. Revista de Ciências Farmacêuticas Básica e Aplicada 32:297-303. 
Burrel Serrat E (2008) Salud, enfermaria y terapia neural. Disertación.

Bravo-Monsalvo A, Vázquez-Chagoyán J, Gutiérrez L, Sumano H (2008) Clinical efficacy of neural therapy for the treatment of atopic dermatitis in dogs. Acta Veterinaria Hungarica 56:459-469.

Canali LCF (2015) A interferência do sangue e soro fisiológico na solubilidade, pH e componente iônico das obturações retrógradas de MTA branco Ângelus ${ }^{\circledR}$. Dissertação, Universidade Estadual de Maringá.

Cassuto J, Sinclair R, Bonderovic M (2006) Anti-inflammatory properties of local anesthetics and their present and potential clinical implications. Acta Anaesthesiologica Scandinavica 50:265-282.

Castro RA (2011) Bases para la terapia neural em caninos y felinos. Buenos Aires: Dunken.

Chang DC (1989) Cell poration and cell fusion using an oscillating electric field. Biophysical Journal 56: 641-652.

Cruz Y, Fayad RN (2011) Microtúbulos y Terapia Neural: propuesta de uma investigación promisoria. Revista Med 19: 82-92.

De La Torres Roses MM, Mendoza RL (2008) La terapia neural: uma alternativa em el tratamiento de La litiasis renal. Revista Arch. Méd. Camagüey 12: 1-9.

Fischer L (2012) Terapia Neural, según Huneke. Fundamentos, técnica, aplicación práctica. México: Hippokrates Verlag Stuttgart.

Garcia JPG, Machado NG (2017) Relación entre la Odontologia neurofocal y los dolores cervicales y de hombro. Acta Médica del Centro 11: 31-38.

Gonçalves BAL, Vianna LR, Andrade CC (2020) Terapia Neural: uma opção de tratamento em pacientes oncológicos. Reviews Multidisciplinary 3: e2020014.

González-Rivas G, Beltrán de Heredia I, Obradors-Giro C, Lóriz-Peralta O (2018) Estudio de intervención no aleatorizado sobre evolución postquirúrgica en pacientes tratadas con terapia neural tras mamoplastia de aumento vía axilar. Non-randomized intervention study on postoperative evolution in patients who underwent neural therapy after transaxillary breast augmentation. Cir plást iberolatinoam 44: 443- 448.

Lebar AM, Miklavčič D (2001) Cell electropermeabilization to small molecules in vitro: control by pulse parameters. Radiology and Oncology 35:193-202.

Muri EMF, Sposito MMM, Metsavaht L (2010) Efeitos secundários potencialmente desejáveis dos anestésicos locais. Acta Fisiatr 17: 28-33.

Pavlin M, Slivnik T, Miklavčič D (2002) Effective conductivity of cell suspension. IEEE Transactions on Biomedical Engineering 49:7780.

Pavlin M, Maša K, Reberšek M, Puchihar G, Hart FX, Magjarević R, Miklavčič D (2005) Effect of cell electroporation on the conductivity of a cell suspension. Biophysical Journal 88:4378-4390.

Reuter URM, Oettmeier R, Nazlikul H (2017) Procaine and Procaine-Base-Infusion: A Review of the Safety and Fields of Aplication after Twenty Years of Use. Sciforschen Clinical Research 4:1-7.

Ramos A, Suzuki DOH, Marques JLB (2006) Numerical study of the electrical conductivity and polarization in a suspension of spherical cells. Bioelectrochemistry 68: 213-217.

Suzuki DOH (2009) Estudo da condutividade elétrica de suspensões de eritrócitos de ratos durante aplicação de campos elétricos intensos: teoria, modelagem e experimentação. Tese submetida à Universidade Federal de Santa Catarina como parte dos requisitos para a obtenção do grau de Doutora em Engenharia Elétrica. Florianópolis.

Sanchez TG, Leray I, Ronchetti M, Cadossi R, Mir LM (2019) Impacto of the number of electric pulses on cell electrochemotherapy in vitro: limits of linearity and saturation. Elsevier p. 31.

Vianna LR, Gonçalves BAL (2016) Nasce uma nova especialidade na Medicina Veterinaria Brasileira: Terapia Neural e Odontologia NeuroFocal. Revista V\&Z Minas 130:16-21.

Vianna LR, Gonçalves BAL (2017) Entenda a terapia neural. Revista CFMV 74 :44-47.

Weinschenk S (2012) Neural therapy - a review of the therapeutic use of local anesthetics. Acupuncture and related therapies 1: 5-9. 